\title{
Critical issues in the relationships between patient relatives and hospital staff: qualitative research based on focus group
}

\author{
Beatrice Cecchini, ${ }^{1}$ Valeria Del Longo, ${ }^{1}$ Emanuela Grandesso, ${ }^{1}$ Alessandro Gamba, ${ }^{1}$ Andrea Semplicini ${ }^{1,2}$ \\ ${ }^{1}$ Internal Medicine 1, USL12 Veneziana, Venice; ${ }^{2}$ Department of Medicine, University of Padua, Italy
}

\begin{abstract}
In Italy the number of elderly patients is increasing and often a family member, also called primary caregiver (CG), assists them. The aim of this study is to describe the peculiar relationships between the family primary CG and the hospital staff, when an elderly patient is admitted to hospital, to demonstrate how this may affect his/her clinical management during the hospital stay and formulate new research projects and organizational rearrangements.
\end{abstract}

\section{Introduction}

Recent studies have reported that families are the main providers of long-term care to dependent elderly people in Italy. The family caregiver (CG) can be defined as either natural or primary.

The primary $\mathrm{CG}$ is an active manager whose main task is to take full responsibility for the well-being of the person in need of care who is in a state of temporary or permanent difficulty within the family unit. Collectively, the term CGs indicates the persons who provide care and who actually care for the

Correspondence: Andrea Semplicini, Medicina Interna 1, Ospedale SS. Giovanni e Paolo, Campo SS. Giovanni e Paolo, Castello 6777-I, 30122 Venezia, Italy.

Tel.: +39.041.5294360 - Fax: +39.041.5294651.

E-mail: andrea.semplicini@unipd.it ;

andrea.semplicini@ulss12.ve.it

Key words: caregiver, focus group, frailty.

Contributions: $\mathrm{BC}$ chaired the focus group, revised tape recordings and wrote the paper; VDL, EG, AG selected the participants for the focus group, collected the participant consent and revised the paper; AS set up the research protocol and revised the paper.

Conflict of interests: the authors declare no potential conflict of interests.

Received for publication: 30 October 2012.

Revision received: 20 November 2013.

Accepted for publication: 13 December 2013.

This work is licensed under a Creative Commons Attribution NonCommercial 3.0 License (CC BY-NC 3.0).

CCopyright B. Cecchini et al., 2014

Licensee PAGEPress, Italy

Italian Journal of Medicine 2014; 8:182-188

doi:10.4081/itjm.2014.99 patients, offer support and affection and are not just directly involved in daily activities or simply act as contact persons. ${ }^{1}$

In general the family $\mathrm{CG}$ experiences substantial interferences with his/her different roles (business, family, etc.). This highlights the multidimensional nature of caring with its practical, organizational, emotional and relational implications, which are closely intertwined in a mix of work and love. ${ }^{2}$ As some authors have stated in the literature, nothing like a serious illness of an elderly person can elicit reciprocity between generations and show that the family is the most important context within which the disease occurs and can be resolved. ${ }^{3,4}$

The various forms of care between family members are multi-faceted and can be summarized as follows: i) care for dialogue - the adult as parent; ii) care for difference - the adult as spouse; iii) care for gratitude - the adult as son. ${ }^{5}$

The relationships of care can be either good or bad according to the following critical elements: i) affective relations with the elderly without open issues; ii) affective relations with the elderly characterized by dependence and need for control; iii) awareness/lack of awareness of caretaking by CG. ${ }^{5}$

The CG experiences a complex family situation and shares daily life with the sick person, becoming a resource and an essential partner in the design of any intervention plan. The family CG needs socioeconomic support, training to identify stressors, and clinical information on drug management and administration, management of postsurgical periods, equipment instructions and functions. ${ }^{6}$ This aims to take care of CGs with both psycho-educational and psychotherapeutic interventions that help them reduce fatigue, depression and stress. ${ }^{6}$

The family member who takes care more consistently of the patient is the primary reference person for the medical personnel, when his/her senior 
arrives at the hospital ward. The CG has behavioral traits that resemble those of the patient or those considered desirable for the patient. ${ }^{7}$

$\mathrm{He} / \mathrm{she}$ may express non-verbally the need for approval of the way he/she supports the patient. The CG may help the patient understand even a complex clinical situation, contextualize it in his/her everyday life and make autonomous health-related choices with piece of mind. These skills are extremely relevant to provide an adequate care to a sick person.

The doctor must learn to consider the CG as a psychological support for the patient, even when he/she is the only direct contact with whom to make decisions for a patient who is at an advanced age or in an impaired mental status. The healthcare team needs to handle effectively any situation that may arise, and encourage the cooperation and trust of the patient and his/her family by maintaining proactive communication and thorough information.

The specific role of the CG of an elderly patient creates a delicate and complex situation in the hospital ward. The CG must take responsibility for medical decision-making and decide what is fair, appropriate and possible in a state of aggravated fatigue. Decisionmaking requires focused attention, but a family member as such may experience conflicting choices, feelings of ambivalence, unresolved conflicts, and subtle family dynamics. Ultimately, the CG and the family in general may not have the required emotional competence, therefore may not take adequate action under this kind of stressful conditions.

These factors may hinder a smooth relationship between the CG and the healthcare team. They can cause misunderstandings or false expectations about tasks and responsibilities, because the CGs have not a compatible workload or cannot rely on a suitable family structure. They may ask for organizational arrangements for the patient that are considered inappropriate by the healthcare team or ask for medical devices that are unsuitable to the patient environment, also because they are often technically incompetent.

Therefore we have committed to deepen our knowledge of these peculiar relationships between the patient, the family CG, and the healthcare team using an approach based on focus groups. Our goal was i) to promote communication between experts, ii) to formulate research questions, iii) to identify potential organizational improvements.

\section{Materials and Methods}

We have used a special qualitative research technique based on focus groups with predefined tasks, in order to bring out opinions, attitudes and knowledge of the participants on a specific topic. This builds cooperative and pragmatic knowledge that can be useful for decision-making and planning purposes. ${ }^{8}$

The experts are members of the group that is formed to explore the problem. ${ }^{8}$ They are homogeneous with respect to the research objectives (students, residents, patients) and have an expert knowledge of the investigated topic.

We conducted our survey during three meetings with professionally homogeneous participants, each lasting $90 \mathrm{~min}$, in a neutral environment (the hospital conference room). The group was led by a clinical psychologist, with a special expertise of group leadership, and an assistant in charge of tape recording.

The moderator personally invited by phone all the participants in the survey and explained methods and aims of the meetings. Only a small number of participants in the CG group accepted the invitation, given the innovative nature of this form of interaction with a public institution, such as the department of internal medicine. The internal medicine unit 1 of the SS Giovanni e Paolo Hospital in Venice has an intense inpatient activity ( 49 beds, over 1400 patients per year, mean age 81) and treats all kinds of acute conditions. The city of Venice has 60,000 residents with an ageing index (ratio between over 65s and under 14s) of 224.8, which is far greater than the national index (148.6). This very particular city has a large percentage of elderly living alone. The younger generations are unlikely to stay in the lagoon area and tend to move to the mainland, from where they face difficulties in taking care of their relatives at home and during a hospital stay.

The three groups were composed of CGs (CG group), physicians (P group), nurses and social workers ( $\mathrm{N}$ group).

The CG group included the wife of a 76-year-old patient hospitalized for 29 days, the son of a 98 -yearold male patient hospitalized for 49 days, the daughter of an 87-year-old male patient hospitalized for 10 days, the daughter of a 92-year-old female patient hospitalized for 7 days. The $\mathrm{P}$ group included 1 male physician with a 2 years' experience in internal medicine, and 3 female physicians, 1 with a 15 years' experience and 2 with a 1 year experience in internal medicine. The $\mathrm{N}$ group included four certified nurses who have worked in an internal medicine department for 18 months, 3, 11, and 22 years, respectively, and a social worker, who has been in this field for 30 years.

\section{Results}

The group with which we worked during the meetings proved that every personal and/or professional experience can offer a valuable and comprehensive contribution from the most important areas of the ward. We extracted some sentences from the tape recording that highlight at best the key aspects of this peculiar 
relationship and drew up a general overview as a basis to formulate operational proposals.

\section{Caregiver group}

A female CG, well aware of the poor health status of her patient, showed a very attentive behavior, charitable more than health-oriented (how to feed, when to ask about the health status, how to move the patient and so on). She was looking for an environment for the end of life care rather than for the treatment of the patient.

...It's an ugly ward. The worst place for people at the end of their lives. Nurses are too busy... They are too familiar with death and used to see patients dying... so, it does not matter if he does not eat... it seems to me that they are not sympathetic and sensitive, in a sense... I am looking for more understanding from this personnel... you stay bedridden in hospital for a couple of weeks, but, if you walked in, why should you be bedridden? The sign with the timetable for enquiries about the patients states between 12 a.m. and 1 p.m., but they show up only at 1.15 p.m.

The son of a 98-year-old patient, hospitalized for 49 days, figured out to be a loving and responsible CG. He saw his father as an active and conscious mentor even at 98 years of age.

...When in deep suffering, as a citizen I used to look at the hospital as a relevant institution, despite its possible fallacies, as they may lack attention to the miserable and sufferer... I was suffering because I was well aware that my father, 98, would die, yet I still hoped to take him home. I understand the fatigue of the woman, but I found room for humanity at the hospital... in hospital you have many more problems with your patient than at home. I do not have much consideration for the physicians. I talked to the medical staff and the chief physician and I was satisfied with the information I received. However, all physicians are arrogant, hard with the patients. When you ask to meet an $M D$, it seems that the meeting is granted out of mercy. The attending physicians, by themselves, should address first the relatives when the patient has relatives. My father, 98 and blind, was telling 'I am thirsty' and I was helping him with the straw, but the MD told me 'please get out of here'...

The daughter of an 87-year-old female patient, hospitalized for 10 days, complained of the difficulties in taking care of her mother. She had a heavy personal medical record. She compared hospital care with home care. She focused on facilities and stressed that they were not of minor importance. To her, to regain health it takes a friendly, reassuring and familiar environment.

I came here with two small but solid proposals. A patient admitted to hospital at 5.45 p.m. will certainly get no food. The administration should provide something to eat, something ready, palatable and easy to eat. They should not let a weak patient without food, but they told me that food is the least relevant issue when you are admitted to hospital. Nurses should not try to do everything by themselves when they are not enough... They come in to treat ulcers and we have to get out of the room. I accept that they send out all the others, but they should allow some relatives to stay, since later they will have to take care of ulcers themselves at home. When the patients are discharged they will tell you, 'Do this, do that'. Do not send us out when you treat ulcers, because we have to learn how to do it later at home. The medical records are no longer at the bedside for privacy reasons, but, apart from privacy, they do not want relatives to read them. My mother was not supposed to eat because of her pylorus occlusion, but the food tray was served and the poor soul started eating. Instead relatives may be of help to improve the continuity of care, and it may improve assistance and attention.

The daughter of a 92-year-old patient, hospitalized for seven days, perceived herself as a full-time CG. She had a disabled husband and a brother with difficulties. She criticized communication procedures and claimed that she would never come back again. She started off with a complaining attitude, but then she turned out to be eager to listen and speak.

Mom was only a week in hospital and then when they sent her home, she was worse than when she got there. I was alone with her intestinal obstruction. One day they told us 'we will send her home on Monday'. A geriatrician had not seen her and all they did was to put the catheter and give her insulin. They provided me with a special bed, after our complaints. We wanted to put her in a nursing home to have some rest, but there was no place. He ordered a bed with containment sides. He suggested me to hire a caregiver, told me that he did not know what to do and that we would have thought about it in due time. However, how could I have thought about it first, if the woman was self-sufficient? She was definitely dirty, but had no catheter. Now, unfortunately, we are preparing paperwork to put her in a nursing home. I am sixty-six years old and my heart sinks... But it may happen, it is not the hospital's fault that she is getting worse, but they should have put her in another place, because she is now like a little girl.

\section{Physicians group}

A female doctor showed understanding for the role of the CG. She clearly argued that the main difficulties arise from the lack of an adequate setting (time and space), from too informal and personal communication with the $\mathrm{CG}$, which, on the contrary, always requires a professional approach. 
... The conflict is most intense when the relatives are only interested in placing their elderly anywhere anyhow. They are interested in solving the social problem more than the disease... family members do not trust the doctor. You may have to deal with someone who claims to know more than you do or who gives us therapeutic suggestions. They are biased about your ability, or about what they have heard about you or health in general... the relatives may give you very important information. Another relevant thing we have to face is that you need to have a decent conversation, it takes time, and unfortunately, we have no time. We are busy with all the activities, which are required for both care and bureaucracy and phone calls, and then you find yourself in trouble when you meet the family. I, personally, would like to have more time to spend for the family interview; I feel to be the sign of a situation that is due to limited economic resources and overwhelming bureaucracy, and certain needs that are more important than our professional quality. I am more disappointed for the conflicts than the relatives are. Communication with relatives requires the utmost honesty on our part and on the part of relatives. We have a reserved space for interview. The interview with relatives is scheduled when we are too busy. We wish we had an hour to spend with the patient family... at school, the teacher reserves an hour for parent interviews.

One doctor revealed a skillful approach and took distance from the dynamics and complications that the CGs could sometimes create. The hospital stay is often at the end of a long and tiring course of treatment which started at home. He suggested strategies to ease the tension between the $\mathrm{CG}$ and the doctors.

...I have no major conflicts with relatives; at least I do not seem to have them. It is true that it takes a lot of patience... Personal characteristics come into play... There are those who are able to go on for a while and then they quit. For the same medical procedure, what makes the difference is precisely the relationship with the relative... not everyone can afford a paid caregiver on top of the expenses to manage the family... While on call it is annoying to talk to relatives of patients that are not under your personal responsibility... you lose five minutes, but the relative goes away a bit happier and does not scream in corridors 'there is no one here'.

Another doctor emphasized that he came from another area, and highlighted the need for greater collaboration between the hospital staff and the local social assistance unit.

I would have liked to have more information on how the social network works in this local healthcare unit, the available facilities, etc. Enquiries about patients are between 12 a.m. and 1 p.m. but it can be hard to talk between 12 a.m. and 1 p.m. ... A doctor can be poorly considered because he has conflicts with relatives, another, maybe less expert, is kept in greater consideration, because he is calm and sweet with relatives.

One doctor was in a more marginal position, because she was dividing her working time between the outpatient clinic and night swifts on call, but she still asked how a CG can interact with colleagues.

...For most of my time, I work in the outpatient clinic. Therefore, I am in the inpatient ward only for day and nighttime calls. For me it is very difficult to give information, mainly because I have many things to oversee while on call. The time needed to give adequate information is not much... There are relatives in any rooms and when they see a doctor... then, there are ten others who want information, too... and you are no longer able to work... it's hard to know the diagnostic and therapeutic plans of each patient... Often the relatives make requests just to have a confirmation of what they had already been told.

\section{Nurses and social workers group}

A registered nurse, described by colleagues as being fresh from college and provocative, perfectly pointed out the importance of working with the $\mathrm{CG}$ as an integral part of the new role of the nurse. He described the $\mathrm{CG}$ as a social condition that is typical of many patients who come to the hospital and pointed out that he/she is welcomed.

...Many family members are a resource, especially at certain times of the day. It may be once in a day. The national health system intends to promote a dialogue... From the architectural point of view we have all glass nursing stations, they knocked down the walls just to encourage the exchange... they have pinpointed misinformation of patients and relatives... it is intrinsic to the service. You cannot deny answers... The point starts from three factors according to me: times, type of patient and number of family members or CGs. As for the number of CGs in any situation, one is more than enough, since we have rooms with two or three patients... There are patients who need $24 / 7$ assistance... patients who need visits limited to only two or three hours a day... We could accept one $C G$ per patient, and the relative should not stay longer than three hours, so as not to hinder our work.

A social worker reported hard work causing poor self-esteem and complained about the lack of respect and recognition for the most difficult tasks performed.

...Relatives are good to feed, but they address you in a bad manner. I have thirty years of seniority. When I have to say something important, I always refer to the certified nurses. They tell me what I have to report to them. The caregivers do what they want; they take things without asking and without thanking you. Awesome... once, they were more respectful of time schedules, it was closed, we are now like in a shopping mall. 
A registered nurse who had just graduated from university presented his tasks as being technological.

...You go along with your trolley and they browse through the drug therapy. They cannot see us sitting. Next year what will they say when we will be managing medical records on the computer, when we will be copying the data in the folder? If there are relatives around, you need double time for drug distribution... when you're walking around in the evening or during the night shift, you set them well to sleep better, have a short chat, reassure them, but they do not consider the nurse, they will respect the doctor, they interrupt you while you prepare the drugs, because they do not consider the nurse and his/her work...

Another nurse reported his experience from the point of view of the patient recalling when he was at the hospital as a patient. He enlivened the group which was a little bit depressed at that time.
...Relatives can be a resource, we are few and a family member who helps you is fine. The relatives have doubts. Did you give him/her the drops to sleep? Free access to the hospital ward shows that you do not treat them badly, shows them how you work, but there is also the other side of the coin,... If they are always around, you give information, but at times you are overwhelmed by things to do... Family members need to be given information in a quieter and calmer environment, once a week, during a meeting with family members if they have questions on the treatment after discharge... you could propose that there is a nurse available to talk with relatives... We should promote citizen education... Sometimes they are also happy, sometimes the family members say 'I will give you a hand. Tell me how to do it'. There are not only negative cases, there are some relatives who come back to say bye.

Table 1. Main problems emerging in the focus groups.

\section{Difficulties of family CGs}

1. Poor knowledge of the principles of bioethics and privacy

2. Idealization of the hospital environment and the activities influenced by the media

3. Anxiety generated by ignorance and fear of care activities that will be required at home after discharge

4. Improper request of social support from the hospital, which is primarily involved in healthcare assistance

5. Suspicion of malpractice influenced by the media

6. Request for written and systematic information

Difficulties of the medical staff

1. Burn out

2. Difficulty in distinguishing medical problems from social assistance for which specific training and knowledge of the local network is needed

3. Lack of a single reference $C G$ with whom to arrange a communication schedule

4. Logistic challenges (regarding environment and time) for communication with the family CG (asynchronous with care activities, yet synchronous with the patient)

5. Inadequate training about bioethics and privacy law requirements

6. Poor knowledge of the role and stress of the family CG and his/her social situation

7. Difficulties in working in team and sharing diagnostic and therapeutic decisions

8. Insufficient recognition of communication activities, not strictly related to medical assistance

\section{Difficulties of the nursing staff and social workers}

1. Consideration of family members as a resource and substitute but concern over the presence of people inadequately prepared in a high-tech setting

2. Burn out and lack of recognition

3. Failure to comply with visiting hours

4. Difficulty in training the relatives at discharge on drug administration and wound medication at home

5. Logistics not optimal for monitoring patients and CG

6. Difficulty in identifying the reference family CG with whom to establish preferential relationship

CGs, caregivers. 
A certified nurse voiced his fatigue and his professional disenchantment with a certain irony. $\mathrm{He}$ made specific requests to reorganize certain things, but he was also helpful in finding solutions.

...There is a timetable. I told them many times! At the time of drug distribution, you are at risk of mistakes. He has the right to ask, 'Why don't you give me the tablet I was taking at home?' They can check you. 'At home, I was doing this'... In some settings, there is a discharge letter written by the nursing staff that reports the point of view of the nurse.

The problems encountered in the relationship between CGs and the healthcare personnel are summarized in Table 1.

\section{Discussion and Conclusions}

The information collected by any qualitative survey based on focus groups cannot be submitted to a formal statistical analysis. However the focus group was the ideal tool to explore relational difficulties among CGs, physicians and nursing staff, as all participants were interested in listening, improving and optimizing their own roles.

We have analyzed the meetings by asking ourselves three questions: i) Which information emerged, based on the initial cognitive requirements? ii) At what depth were the topics of interest approached? iii) What conclusions can be drawn? ${ }^{9}$

The CGs stressed the significant emotional dimension involved in the experience of having a hospitalized spouse. They put great emphasis on the daily organization of the department (meal distribution, visiting hours, cleaning procedures), affecting both the CG and the elderly patient, and paid particular attention to the details of their relationship with the healthcare providers and their personal involvement in daily assistance. The CGs felt to be part of the care process beginning when their relative was at the hospital and continuing at home. However, the CGs were completely unaware of the stress that they had already accumulated because of the long and arduous effort required to take care of their relative beforehand. They attributed their level of stress only to the hospital admission and the relationship with the ward personnel.

The $\mathrm{P}$ group highlighted their effort and commitment in addressing the CG, seen as a new task in their role which they had never experienced when they were studying. They also emphasized the emotional burden which derives from managing the relational dynamics with relatives which is always new when they meet a new family. They expressed their willingness to learn, also by exchanging experience or proposing shared procedures or common styles of communication. They voiced the need to have suitable times and places especially to talk with the CGs about end of life issues. As to the organizational improvements, the results highlighted the need to have a meeting place to talk to CGs (with a well-defined place and time), compatible with their duties, style of communication and organization needs, to promote a comprehensive and relaxed communication. Lastly, they called for greater integration with the local community services.

The $\mathrm{N}$ group also emphasized the relevance of the suffering of the patient and the CG elicited by hospitalization on the basis of their personal experience as patients. The collaboration with the $\mathrm{CG}$, recognized as a valuable ally in daily activities, was seen from the point of view of the nurse who has an increasingly technical and independent role. In this regard, nurses recommended to reserve adequate time and space to talk with the CGs through educational meetings and adequate information materials. The group has also demanded well-defined procedures to take care not only of the patient but also of CGs at the time of admission and discharge to promote continuity of care and healthcare education to users.

Therefore we propose the following initiatives to enhance the participative approach of focus groups:

- Establishment of a multidisciplinary working group that will define an individualized project of care to be agreed with CGs. It will define time and activities of CGs in the ward taking into consideration the specific needs of the other patients and his/her relatives as well as the needs of the department organization.

- Definition of a well-defined time and space (at a convenient time during the week, with the doctor and the nurse alone or together) to discuss general issues concerning care and treatments provided in the department.

- Enhancement of teamwork in collaboration with the family.

- Establishment of ways to acknowledge and thank each other as ideal factors of care.

A limit of our qualitative research approach is the small number of participants in the focus groups, which included only a small number of the many stakeholders involved. Therefore we could not analyze statistically the results, but the focus groups demonstrated to be feasible in a hospital setting and reproducible in other social settings.

In conclusion, we propose to follow-up this survey, because of the fruitful participation of all stakeholders, which emphasized its relevance and necessity. We consider that the attention to communication is the ultimate achievement of an outstanding professional approach which is already shared by many public health workers, who need to be better acknowledged in the society at large. 


\section{References}

1. Taccani P, Tognetti A, De Bernardinis S. Curare e prendersi cura: Relazione con l'anziano e la sua famiglia. Roma: Carocci; 1999.

2. Taccani P. Figli adulti e genitori anziani: c'è del lavoro da fare. Adultità 2006;24:132-40.

3. Walsh F. Stili di funzionamento familiare: come le famiglie affrontano gli eventi della vita. Milano: Angeli; 1993.

4. Cigoli V. Il corpo familiare: l'anziano, la malattia, l'intreccio generazionale. Milano: Angeli; 1992.

5. Micheli GA. La questione anziana: l'automutuo aiuto in gruppo di familiari che svolgono il lavoro di cura. Milano: Angeli; 2004.

6. AA.VV. Valorizzare e sostenere i caregiver. Animazione Sociale 2002;2:10-3.

7. Scabini E. Psicologia sociale della famiglia. Torino: Boringhieri; 1995.

8. Cataldi S. Come si analizzano i focus groups. Milano: Angeli; 2009.

9. Acocella I. Focus groups: teoria e tecnica. Milano: Angeli; 2008. 